Comprendemos la postura del maestro Golsdchmidt, en el sentido de la internacionalización y la convivencia entre las naciones.-

Sin embargo, este proceso de globalización tiene, o debiera tener, limites.La necesidad de un "Espacio" en un mundo globalizado es algo que ha sido advertido frecuentemente en la etnología y en la antropología contemporánea ${ }^{34}$; el hombré necesita un lugar, y lo diseña como modo de protección.- De allí el paradójico surgimiento de los nacionalismos, regionalismos, en el contexto de una tendencia global.-

No todo es materia de integración y ni siquiera de armonización.- Cada comunidad tiene su fisonomía propia, sus costumbres, cultura, proyectos de vida, que desea preservar frente a la integración.-

Es razonable que esto sea mantenido respetando la voluntad de los pueblos en este sentido, lo que justifica el mantenimiento del orden público interno en aspectos como los referidos.-

\section{La idea del ejercicio abusivo del orden público}

En estos cambios paradigmáticos que describimos, es interesante examinar la idea del uso abusivo del orden público.-
Si el objetivo es la integración y ello constituye una obligación jurídica de los Estados-Partes, es claro que el orden público estatal debe ser usado para la protección de valores que esa comunidad tiene y que no desea compartir.-

Estos son los fines que se le reconocen al orden público: protección de la moral, buenas costumbres, validez de los actos, espíritu de las leyes, todo lo cual puede ser resumido en una cultura propia, nacional o regional.- Este concepto se desnaturaliza cuando, con el pretexto de conservarlo se lesionan los derechos individuales, de un modo tal que no sólo se los restringe, sino que se los ahoga postulando la existencia de un orden público sin individuos.

De la misma manera, puede ser usado contra los fines que la ley tuvo en miras al reconocerlo, cuando se transforma en un instrumento para restringir indebidamente el acceso al mercado de una empresa que goza derecho de trato nacional.

El Tribunal de Justicia de la Comunidad Europea, en la causa "Rutili", estableció que para que el orden público pueda limitar la libre circulación debe ser usado frente a una "amenaza ral y suficientemente grave que afecta a un interés fundamental de la sociedad".

\title{
Colisão de Direitos Fundamentais e Realização de Direitos Fundamentais no Estado de Direito Democrático*
}

\author{
Pobext exlexy \\ Professor de La Universidad Christian - Albrecht de Kiel \\ Tradutor: Dr. Luís Afonso Heck, Prof. na UFRGS e ULBRA
}

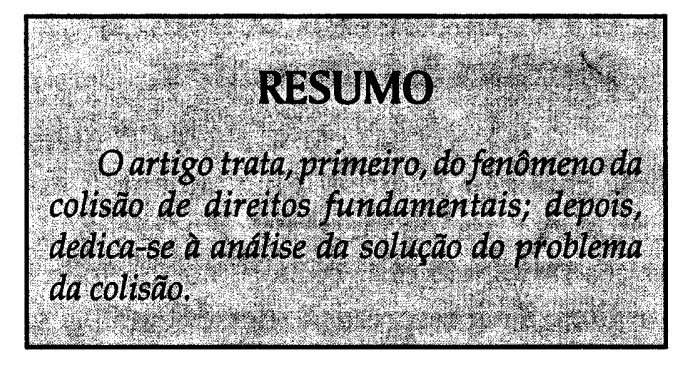

\section{SUMÁRIO}

I. O Fenômeno da Colisão de Direitos Fundamentais;

1. Colisões de direitos fundamentais em sentido estrito; a) Colisões de direitos fundamentais idênticos; $b$ ) Colisão de direitos fundamentais diferentes; 2 . Colisões de direitos fundamentais em sentido amplo;

II. A Solução do Problema da Colisão;

1. A força vinculativa dos direitos fundamentais; 2. Regras e princípios; a) $A$ distinção; b) As opções da teoria das regras; c) O caminho da teoria dos princípios; d) Vinculação e flexibilidade. direitos fundamentais são, por um lado, elementos essenciais da ordem jurídica nacional respectiva. Por outro, porém, eles indicam além do sistema nacional. Nessa passagem do nacional deixam-se distinguir dois aspectos: um substancial e um sistemático. Os direitos fundamentais rompem, por razões substanciais, o quadro nacional, porque eles, se que. rem satisfazer os requisitos que lhes podem ser postos, devem incluir os direitos do homem. Os direitos do homem têm, porém, independentemente de sua positivação, validez universal. ${ }^{1}$ Eles põem, por conseguinte, exigências a cada ordem jurídica. Uma contribuição importante para a sua concretização internacional forneceu e fornece a Declaração Universal dos Direitos do Homem, de 10 de dezembro de 1948. Os direitos do homem tornaram-se

Palestra proferida na sede da Escola Superior da Magistratura Federal (ESMAFE) no dia 07 de dezembro de 1998.

1. Comparar R. Alexy, Diskurstheorie und Menschenrechte, in: ders., Recht, Vernunft, Diskurs, Frankfurt a.M. 1995, S. 144 f. 
vinculativos jurídico-positivamente no plano internacional pelo Pacto Internacional sobre Direitos Civis e Políticos, de 19 de dezembro de 1966. Uma peça paralela a ele é o Pacto Internacional sobre Direitos Econômicos, Sociais e Culturais, do mesmo dia, que, naturalmente, está dotado com muito menor força de concretização. Ao lado deles e de outros pactos delineados internacionalmente colocam-se convenções regionais. Tudo isso cria comunidades substanciais.

Às comunidades substanciais correspondem as sistemáticas. Em toda a parte onde direitos fundamentais existirem, colocam-se os mesmos ou semelhantes problemas. Apenas para mencionar alguns: que diferenças estruturais existem entre direitos de defesa liberais, direitos à proteção, direitos fundamentais sociais e direitos de cooperação política? Quem é o destinatário, quem o titular de direitos fundamentais? Sob quais pressupostos formais e materiais direitos fundamentais podem ser limitados? Com que intensidade pode um tribunal constitucional controlar o legislador sem que sejam violados o princípio democrático e o princípio da separação de poderes? A comunidade de semelhantes questões sobre a estrutura de direitos fundamentais e jurisdição constitucional abre, diante do fundo das comunidades substanciais, a possibilidade de uma ciência dos direitos fundamentais transcendente às ordens jurídicas particulares, a qual é muito mais que uma mera comparação de direito. ${ }^{2}$ É a ciência dos direitos fundamentais

ampla. $\mathrm{O}$ objetivo da ciência dos direitos fundamentais ampla não é, de nenhum modo, a nivelação das ordens dos direitos fundamentais. Ao contrário, as diferenças lhe dão estímulos e tarefas. Seu intento vale, antes, à revelação das estruturas dogmáticas e ao destacamento dós princípios e valores que estão atrás das codificações e da jurisprudência. $\mathrm{O}$ intrincado e complicado pode, assim, converter-se em uma multiplicidade sistematicamente preenchida e, com isso, entendida no melhor sentido que, dessa forma, compreende-se, simultaneamente, como unidade.

\section{O Fenômeno da Colisão de Direitos Fundamentais}

A maioria das constituições contêm hoje catálogo de direitos fundamentais escritos. A primeira tarefa da ciência dos direitos fundamentais, como uma disciplina jurídica, é a interpretação desses catálogos. Nisso, valem as regras tradicionais da interpretação jurídica. Estas, todavia, na interpretação dos direitos fundamentais, chocam-se logo com limites. Uma razão essencial para isso é a colisão de direitos fundamentais.

O conceito de colisão de direitos fundamentais pode ser compreendido estrita ou amplamente. Se ele é compreendido estritamente, então são exclusivamente colisões nas quais direitos fundamentais tomam parte colisão de direitos fundamentais. Pode-se falar aqui de colisões de direitos fundamentais em sentido estrito. Em uma compreensão ampla são, pelo contrário,

2. Comparar P. Häberle, Verfassungsentwicklung in Osteuropa - aus der Sicht der Rechtsphilosophie und der Verfassungslehre, in: AŌR 117 (1992), S. $170 \mathrm{ff}$.

também colisões de direitos fundamentais com quaisquer normas ou princípios, que têm como objeto bens coletivos, colisões de direitos fundamentais. Isso é o conceito de colisão de direitos fundamentais em sentido amplo. Ambos os tipos de colisão são temas centrais da dogmática dos direitos fundamentais. Sua análise conduz a quase todos os problemas dessa disciplina. Todavia, antes de iniciar essa análise, deve, primeiro, o fenômeno a ser analisado ser considerado mais de perto.

Não existe catálogo de direitos fundamentais sem colisão de direitos fundamentais e também um tal não pode existir Isso vale tanto para colisões de direitos fundamentais em sentido estrito como também para tais em sentido amplo.

\section{Colisões de direitos \\ fundamentais em sentido estrito}

Colisões de direitos fundamentais em sentido estrito nascem sempre, então, quando o exercício ou a realização do direito fundamental de um titular de direitos fundamentais tem conseqüências negativas sobre direitos fundamentais de outros titulares de direitos fundamentais. Nos direi tos fundamentais colidentes pode tratar-se ou dos mesmos ou de direitos fundamentais diversos.

\section{a) Colisões de direitos \\ fundamentais idênticos}

Deixam-se distinguir quatro tipos de colisões de direitos fundamentais idênticos.
No primeiro tipo está, em ambos os lados, afetado o mesmo direito fundamental como direito de defesa liberal. Uma tal colisão existe, por exemplo, então, quando dois grupos políticos hostis, por um motivo atual, querem demonstrar-se, ao mesmo tempo, no centro de uma cidade e há o perigo de choques. No segundo tipo trata-se do mesmo direito fundamental, uma vez como direito de defesa liberal de um e, outra, como direito de proteção do outro. Um tal caso existe, por exemplo, quando é atirado em um detentor de refém para salvar a vida de seu refém. Nisto, contudo, deve ser acentuado que com a colisão entre o direito à vida, de um lado, do detentor do refém, e, de outro, do refém, somente é compreendida uma parte do problema total. É freqüentemente possível salvar a vida do refém pelo fato de simplesmente atender às exigências do detentor do refém. Vem, então, como terceiro elemento da colisão total uma "obrigação de proteção (...) diante da totalidade dos cidadãos" 3 em jogo, que pede do Estado não fazer nada que possa dar estímulo a outras tomadas de reféns. $\mathrm{O}$ objeto imediato desse dever de proteção é um bem coletivo: a segurança pública. Isso torna claro que muitas colisões são complexas. Exatamente para compreender adequadamente colisões complexas, porém, é necessário identificar claramente os elementos fundamentais dos quais elas são compostas. Oterceiro tipo de colisão de direitos fundamentais iguais resulta disto, que muitos direitos fundamentais têm um lado negativo e um positivo. Isso é especialmente claro na liberdade de crença. Ela compre-

3. BVerfGE 46,160 (165). 
ende tanto o direito de ter e de praticar uma crença, como também o direito de não ter uma crença e de ser poupado da prática de uma crença. Quais problemas podem resultar disso mostra a resolução-crucifixo, uma das decisões mais discutidas do Tribunal Constitucional Federal alemão, ${ }^{4}$ com toda a clareza. Nesta decisão trata-se da questão se o Estado pode ordenar que nas salas de aula de escolas públicas deve ser colocada uma cruz. Aqui colide a liberdade de crença negativa dos não-cristãos que, assim o Tribunal Constitucional Federal, "em classe, por ordem do Estado e sem possibilidade de evitar, são confrontados com esse símbolo e são obrigados a aprender 'sob a cruz", 5 com a liberdade de crença positiva dos cristãos, "de praticarem sua convicção de crença no quadro das instituições estatais". ${ }^{6} \mathrm{O}$ tribunal dissolve essa "relação de tensão entre liberdade religiosa negativa e positiva" ao proibir a colocação de cruzes ou crucifixos em espaços escolares públicos, em que, para a fundamentação, outros pontos de vista são aduzidos, especialmente aquele da neutralidade religioso-política. ${ }^{8}$ A quarta variante de colisões dos mesmos direitos fundamentais de titulares diferentes resulta quando se acrescenta ao lado jurídico de um direito fundamental um fático. Como exemplo, seja considerada a jurisprudência do Tribunal Constitucional

Federal alemão sobre auxílio de custas processuais. Se se parte da igualdade jurídica, então pobres e ricos são tratados igualmente quando nenhum deles recebe apoio estatal para o financiamento de custas judiciais e honorários de advogado. Sob o ponto de vista da igualdade fática, porém, isso é um tratamento desigual, porque do pobre, com isso, as oportunidades de concretizar seu direito são tomadas ou estreitadas. ${ }^{9}$ Se se fomenta, porém, o pobre, entẫo tratam-se os ricos juridicamente de outra forma, portanto, desigualmente, porque: "Fomentar determinados grupos significa já tratar outros desigualmente." 10 Se se estende o princípio da igualdade tanto à igualdade jurídica como à fática, então topa-se forçosamente com esse paradoxo da igualdade. O paradoxo da igualdade é uma colisão que se apresenta tanto mais intensamente quanto mais é realizado em Estado social. Não é, portanto, acaso que o Tribunal Constitucional Federal alemão enlaça a idéia da igualdade fática com o princípio do Estado social. ${ }^{11}$

\section{b) Colisão de direitos \\ fundamentais diferentes}

Sob as colisões entre direitos fundamentais diferentes de titulares de direitos fundamentais diferentes, a colisão da liberdade de manifestação de opinião com direi-

. Comparar, para isso, Winfried Brugger/Stefan Huster ( $\mathrm{Hg}$.), Der Streit um das Kreuz in der Schule, Baden-Baden 1998.

5. BVerfGE 93,1 (18).

6. BVerfGE 93,1 (24)

7. BVerfGE 93,1 (22)

8. Ebd.

9. BVerfGE 56,139 (144).

10. BVerfGE 12,354 (367)

11. BVerfGE 12, 354 (367); 56,139 (143) tos fundamentais do afetado negativamente pela manifestação de opinião toma uma posição especial. É essa a problemática que, em 1958, deu motivo ao Tribunal Consti tucional Federal com sua sentença-Lüth, ${ }^{12}$ uma das sentenças mais significativas da jurisdição constitucional alemã, de colocar os trilhos básicos para a sua jurisprudência da ordem de valores que conduz a duas conseqüências fundamentais para os direitos fun damentais: primeiro, à irradiação dos direitos fundamentais sobre o sistema jurí dico total e, segundo, à onipresença da pon deração. Um efeito tardio dessa sentença é a resolução soldados-são-assassinos, na qual a condenação de pacifistas, que qualifica ram soldados de assassinos, por ofensa foi classificada como inconstitucional. Aqui colide a liberdade de manifestação de opinião (art. 5으, alínea 1, frase 1, da Lei Fundamental) dos pacifistas com o direito de personalidade geral (art. 2을 alínea 1 , em união com o art. $1^{\circ}$, alínea 1 , da Lei Fundamental) dos soldados, que inclui a proteção da honra. ${ }^{13} \mathrm{O}$ debate exacerbado, que essa sentença promoveu, mostra que material explosivo colisões de direitos fundamentais podem ocultar.

$\mathrm{Na}$ resolução soldados-são-assassinos trata-se de uma colisão de direitos de liberdade diferentes de titulares de direitos fundamentais diferentes. Colisões de direitos fundamentais diferentes de titulares de direitos fundamentais diferentes existem não só no âmbito dos direitos de liberdade. Elas são possíveis entre direitos fundamentais de

12. BVeriGE $7,198$.

13. BVerfGE 93,266 (290).

14. BVerfGE 58,300 ( 318 ff.) qualquer tipo. Especialmente importante é aquela entre direitos de liberdade e igualdade. Se se aplica a proibição de discriminação à ordem jurídica total, portanto, também ao direito privado, então colisões entre a autonomia privada do empregador e o direito ao tratamento igual do empregado são inevitáveis.

\section{Colisões de direitos \\ fundamentais em sentido \\ amplo}

Até agora tratou-se de colisões de direitos fundamentais em sentido estrito, portanto, de colisões entre direitos fundamentais iguais e diferentes de titulares de direitos fundamentais diferentes. Não menos significativas são as colisões de direitos fundamentais em sentido amplo, portanto, as colisões de direitos fundamentais com bens coletivos. Um exemplo para isso oferece a resolução da dragagem do Tribunal Constitucional Federal alemão. Nela tratouse da questão de em qual proporção e como o legislador pode proibir ao proprietário aproveitamentos de seu terreno que prejudicam a água subterrânea. ${ }^{14} \mathrm{~A}$ qualidade da água é um bem coletivo clássico. A visão, que se torna sempre mais penetrante, sobre problemas ecológicos, eleva sempre mais colisões desta natureza de bens coletivos ecológicos com o direito fundamental à propriedade à luz.

Bens coletivos não são só, natural. mente, adversários de direitos individuais. Eles também podem ser pressuposto ou meio 
de seu cumprimento ou fomento. ${ }^{15}$ Assim, o dever legal da indústria de tabacos de colocar advertências sobre prejuízos à saúde em seus produtos é uma intervenção na liberdade de exercício profissional dos produtores de tabaco, portanto, em um direito fundamental. A justificação direta dessa intervenção reside na "proteção da população diante de riscos à saúde", ${ }^{16}$ portanto, em um bem coletivo. Indiretamente, trata-se, nisso, de algo que também por direitos individuais é protegido, ou seja, da vida e da saúde do particular. O mais claro é o caráter ambivalente no bem coletivo clássico da segurança interna ou pública. $O$ dever do Estado de proteger os direitos de seus cidadãos obriga-o a produzir uma medida tão ampla quanto possível deste bem. Isso, porém, não é possível sem intervir na liberdade daqueles que prejudicam ou ameaçam a segurança pública.

A segurança interna é um bem coletivo central do Estado de direito liberal. A proteção do meio ambiente define sua variante mais nova: o Estado de direito ecológico. Visto historicamente, entre ambos está o Estado de direito social. O cumprimento dos postulados do Estado de direito social apresenta poucos problemas quando um equilíbrio econômico cuida disto, que todos os cidadãos mesmos ou por sua família estejam dotados suficientemente. Quanto menos isso é o caso, tanto mais os direitos fundamentais sociais pedem redistribuição. Disto existem duas formas básicas. A pri- meira ocorre quando o Estado, por impostos ou outras contribuições, consegue o dinheiro que é necessário para atender ao mínimo existencial dos pobres. $O$ dever de pagar impostos, porém, intervém em direitos fundamentais. Duvidoso é somente quais são eles: o direito de propriedade ou a liberdade de ação geral. ${ }^{17}$ Como o Estado lidade do cumprimento de postulados estatal-sociais, não é conveniente aduzir diretamente os direitos fundamentais sociais para a justificação dessa intervenção. Antes, a cobrança de impostos serve diretamente só à produção da capacidade de ação financeira do Estado. A capacidade de ação financeira do Estado é, em termos genéricos, um pressuposto de sua capacidade de ação. $O$ Estado social pede que ela seja

A segunda forma da redistribuição estatal-social não sucede pelo erário público, que é enchido de antemão por impostos ou outras contribuições, senão diretamente de um para outro cidadão. Assim, trata-se de uma redistribuição direta de um cidadão para outro cidadão quando o legislador, para a proteção do locatário, promulga prescrições que dificultam o aviso de saída ou limitam as possibilidades do aumento de aluguel. ${ }^{18} \mathrm{O}$ art. $7^{\circ}$ da Constituição brasileira de 05 de outubro de 1988 utiliza intensamente uma redistribuição direta desta natureza ao, por exemplo, o inc. I prescrever uma proteção contra despedinunca cobra impostos somente para a finaconsideravelmente ampliada.

15. Comparar, para isso, R. Alexy, Individuelle Rechte und kollektive Güter, in Recht, Vernunft, Diskurs, Frankfurt a.M. 1995, S. 243 Hf. 16. BVerfGE 95,173 (185)

17. BVerGE 93,121 (137 f.).

18. Comparar BVerfGE 68,361 (367); 89,1 ( 5 ff.). da, o inc. IV um salário mínimo, o inc. XIII um horário de trabalho máximo e o inc. XVII férias anuais remuneradas. O problema de tais direitos fundamentais sociais à custa de terceiros, ou seja, do empregador é que, no fundo, o mercado decide sobre isto, se eles são efetivos. Para aquele que não encontra emprego esses direitos correm no vazio. Aqui deve interessar somente que nesses direitos se trata de uma situação de colisão complexa. Do lado do empregador o assunto ainda é simples. Sua liberdade empresarial é limitada. Um direito não está diretamente diante daquele do lado do empregado, mas somente um direito a isto que ele então, quando achar um emprega dor que o empregue, obtenha um salário mínimo. Isso é um direito social condicio nal. Diretamente pelo art. $7^{\circ}$ somente é criado um bem coletivo, ou seja, um estado da economia no qual - se essa prescrição for observada - existem somente empregos com salário mínimo, em que a questão so bre sua distribuição ainda permanece totalmente aberta.

\section{A Solução do Problema da Colisão}

O olhar sobre o fenômeno da colisão de direitos fundamentais deu à luz constelações altamente diferentes que, porém, têm algo em comum: todas as colisões podem somente então ser solucionadas se, ou de um lado ou de ambos, de alguma maneira, limitações são efetuadas ou sacrifícios são feitos. A questão é como isso deve ocorrer $\mathrm{Na}$ resposta a esta questão devem ser tomadas decisões fundamentais sobre a estru tura fundamental da dogmática dos direitos fundamentais.

\section{A força vinculativa dos direitos}

\section{fundamentais}

A questão mais importante para cada catálogo de direitos fundamentais é se nos direitos fundamentais se trata de normas juridicamente vinculativas ou não. $O$ conceito da vinculação jurídica é determinado diferentemente na teoria geral do direito. Em um sistema jurídico que conhece a separação dos poderes e, com isso, o poder judicial como terceiro poder, tudo fala a favor disto, de qualificar como "juridicamente vinculativas" somente aquelas normas de direitos fundamentais cuja violação, seja em que procedimento for, possa ser verificada por um tribunal, que são, portanto, justiciáveis. É ideal, quando esta verificação, em última instância, é deixada a cargo de um tribunal constitucional, porém, também possível que ela caiba somente na competência dos tribunais profissionais. Normas de direitos fundamentais, cuja violação não pode ser verificada por nenhum tribunal, têm, pelo contrário, um caráter nãojusticiável e são, nisso, vinculativas não juridicamente, senão, talvez, moral ou politicamente. Elas são meras normas programáticas ou, se se quer formular polemicamente, mera lírica constitucional.

O problema da colisão iria, como problema jurídico, desaparecer já totalmente se se declara todas as normas de direitos fundamentais como não-vinculativas. As colisões seriam, então, problemas políticos ou morais e não caberiam, como tais, na competência dos tribunais. Na Alemanha, essa solução é excluída pelo art. $1^{\circ}$, alínea 3, da Lei Fundamental, que vincula todos os três poderes aos direitos fundamentais como direito diretamente vigente. Também 
no Brasil o caminho de uma declaração de não-vinculação de todos os direitos fundamentais deveria ser intransitável, porque o art. 5o, alínea 1 , declara, pelo menos, as prescrições de direitos fundamentais desse art. como diretamente aplicáveis. Mas tam bém independente de ordens de vinculação jurídico-positivas desta natureza a justiciabilidade dos direitos fundamentai deve ser exigida. Direitos fundamentais são essencialmente direitos do homem trans formados em direito positivo. ${ }^{19}$ Direitos do homem insistem em sua institucionalização. Assim, existe não somente um direito do homem à vida, senão também um direito do homem a isto: que exista um Estado que concretize tais direitos. ${ }^{20} \mathrm{~A}$ institucionalização inclui necessariamente justicialização.

Poder-se-ia achar agora que a justiciabilidade não precisa ser total ou ampla. Assim, por exemplo, a cláusula de vinculação do art. 5o, § 1일 da Constituição brasileira, está nos direitos de defesa clássicos e não nos direitos fundamentais sociais. Tal poderia ser entendido como convite a isto, declarar os direitos fundamentais sociais como não-justiciáveis. A nãojusticiabilidade, nisso, poderia estender-se a todos os direitos fundamentais sociais ou a alguns da respectiva constituição. $O$ problema da colisão, com isso, sem dúvida, não estaria totalmente solucionado, porque há, como mostrado, numerosas colisões entre direitos fundamentais de tradição liberal mas ele seria desagravado consideravelmen- te. Colisões estatal-sociais restam possíveis, sem dúvida, conforme o objeto se maioria parlamentar por si, portanto, sem estar obrigado a isso pela constituição, fica ativa no campo da redistribuição estatal-social. O social, porém, teria diante do liberal pouca força, porque ele não poderia apoiar-se em princípios jurídicos. Ademais, colisões estatal-sociais não teriam lugar totalmente se o legislador renunciasse completamente a atividades sociais. Onde não existe dever jurídico nada pode colidir juridicamente. Análogo vale para o lado ecológico da constituição.

A todas as tentativas de desagravar o problema da colisão pela eliminação da justiciabilidade deve opor-se com energia. Elas não são outra coisa senão a solução de problemas jurídico-constitucionais pela abolição de direito constitucional. Se algumas normas da constituição não são levadas a sério é difícil fundamentar por que outras normas também então devem ser levadas a sério se isso uma vez causa dificuldades. Ameaça a dissolução da constituição. A primeira decisão fundamental para os direitos fundamentais é, por conseguinte, aquela para a sua força vinculativa jurídica ampla em forma de justiciabilidade.

\section{Regras e princípios}

A segunda decisão fundamental é se direitos fundamentais têm o caráter de regras ou o de princípios. Na primeira decisão fundamental tratava-se disto: se direitos fundamentais são direitos; objeto da segunda é o que eles são como direito. Não só a
19. R. Alexy, in: Lexikon der Philosophie, hg. v. Hans Jörg Sandkühler, Hamburg 1999 (im Druck).

20. Ders., Die Institutionalizierung der Menchenrechte im demokratischen Verfassungsstaat, in: Stefan Gosepath/Georg Lohmamm (Hg.), Philosophie der Menschenrechte, Frankłurt a.M. 1998, S. 254 ff. solução do problema da colisão senão também as respostas a quase todas as questões da dogmática dos direitos fundamentais geral dependem desta decisão fundamental. Isso esclarece a intensidade e a amplitude da discussão. Aqui devem bastar algumas observações à tese de que a teoria dos princípios dos direitos fundamentais oferece melhor solução do problema da colisão.

\section{a) A distinção}

Segundo a definição standard da teoria dos princípios, ${ }^{21}$ princípios são normas que ordenam que algo seja realizado em uma medida tão ampla quanto possível relativamente a possibilidades fáticas ou jurídicas. Princípios são, portanto, mandamentos de otimização. ${ }^{22}$ Como tais, eles podem ser preenchidos em graus distintos. A medida ordenada do cumprimento depende não só das possibilidades fáticas, senão também das jurídicas. Estas são determinadas, ao lado, por regras, essencialmente por princípios opostos. As colisões de direitos fundamentais supra delineadas devem, segundo a te oria dos princípios, ser qualificadas de colisões de princípios. O procedimento para a solução de colisões de princípios é a ponderação. Princípios e ponderações são dois lados do mesmo objeto. Um é do tipo teórico-normativo, o outro, metodológico. Quem efetua ponderações no direito pressupõe que as normas, entre as quais é pon derado, têm a estrutura de princípios quem classifica normas como princípios deve chegar a ponderações. A discussão sobre a teoria dos princípios é, com isso, essencialmente, uma discussão sobre a ponderação.

Bem diferente estão as coisas nas regras. Regras são normas que, sempre, ou só podem ser cumpridas ou não cumpridas. Se uma regra vale, é ordenado fazer exatamente aquilo que ela pede, não mais e não menos. Regras contêm, com isso, determinações no quadro do fático e juridicamente possível. Elas são, portanto, mandamentos definitivos. A forma de aplicação de regras não é a ponderação, senão a subsunção.

A teoria dos princípios não diz que catálogos de direitos fundamentais não contêm absolutamente regras, portanto, absolutamente determinações. Ela acentua não só que catálogos de direitos fundamentais, na medida em que efetuam determinações definitivas, têm uma estrutura de regras, senão salienta também que o plano das regras precede prima facie o plano dos princípios. ${ }^{23}$ Seu ponto decisivo é que atrás e ao lado das regras estão princípios. A parte correspondente de uma teoria dos princípios é, por conseguinte, não uma teoria que aceita que catálogos de direitos fundamentais também contêm regras, senão uma teoria que afirma que catálogos de direitos fundamentais somente consistem de regras. Exclusivamente tais teorias devem aqui ser qualificadas de "teoria das regras".
21. R. Alexy, Theorie der Grundrechte, 3. Aufl., Frankfurt a.M. 1996, S. 75 f.

22. Um aperfeiçoamento que replica a críticos dessa definiçăo encontra-se em R. Alexy, Zur Struktur der Rechtsprinzipien, conferência no simposio sobre regras, princípios e elementos no sistema do direito, Graz 1997 (no prelo).

23. R. Alexy, Theorie der Grundrechte (nota 21), S. 121 f. 


\section{b) As opções da teoria das regras}

À teoria das regras dos direitos fundamentais estão abertos três caminhos para a solução de colisão de direitos fundamentais: primeiro, a declaração, pelo menos, de uma das normas colidentes como inválida ou juridicamente não-vinculativa; segundo, a declaração, pelo menos, de uma das normas como não-aplicável ou correspondente; e terceiro, a inserção livre de ponderação de uma exceção em uma de ambas as normas.

O primeiro caminho já foi declarado como não-transitável, visto que se trata, nas normas de direitos fundamentais, de normas com hierarquia constitucional e constituições devem ser levadas a sério. Poder-se-ia, talvez, pensar nisto, de renunciar a conteúdos jurídico-fundamentais que foram ganhos por interpretação. Assim, poder-se-ia eliminar, por exemplo, a colisão no caso jurídico dos pobres mencionado pelo fato de se interpretar excluindo cada elemento da igualdade fática do princípio da igualdade. Contra isso falam, todavia, razões fortes. De resto, o problema da colisão não estaria solucionado com isso, porque existem colisões suficientes que não podem ser eliminadas desta forma.

O segundo caminho é seguido quando se reconhece a norma de direito fundamental, também aquela ganha por interpretação, como tal, interpretando esta, então, porém, estritamente. Assim, poderse-ia no caso soldados-são-assassinos pensar nisto, de negar à afirmação de que

24. Comparar, para isso, R. Alexy, Theorie der Grundrechte (nota 21) S. 278 ft. uma exceção, o que, aproximadamente, deixa-se formular como segue: cada um tem o direito de determinar livremente a maneira de seu exercício da profissão, a não ser que se trate de advertências sobre prejuízos à saúde nas embalagens de mercadorias de tabaco. Isso é uma concepção algo bizarra de uma exceção, porque se se qualifica tal como exceção, cada direito fundamental é cercado de uma série quase infinita de exceções. $A$ isso serve mal o conceito de exceção. Aqui, isso, porém, não deve importar. A questão é, pelo contrário, se a "exceção" mencionada antes pode ser fundamentada livre de ponderação. $O$ texto da parte da formulação do direito fundamental que concede ao cidadão a liberdade do exercício da profissão para isso nada dá. Isso vale tanto para o art. 12, alínea 1, frase 2, da Lei Fundamental, como também para o art. 5o, inc. XIII, da Constituição brasileira. Poder-se-ia, porém, achar que o caso se deixa subsumir livre de ponderação sob a cláusula de limitação. Aqui é considerado somente o art. 12, alínea 1 , frase 2 , da Lei Fundamental. Lá diz que o exercício da profissão pode "ser regulado por lei ou com base em uma lei". Se se subsume sob esta formulação, então pode-se, de fato, rapidamente e sem qualquer problema, verificar livre de ponderação que o dever de colocação de advertências em produtos de tabaco é uma regulação com base em uma lei..$^{25}$ Com isso o problema da colisão está solucionado? A teoria das regras venceu?

Deve-se olhar somente sobre as conseqüências de um tal procedimento para reconhecer que isso não é o caso. Doces, cucas e tortas são, segundo convicção propagada, menos sadios para os dentes do que pão. Suponha-se que um partido de fanáticos de saúde ganha a maioria no parlamento. Ele proíbe aos padeiros e todos os outros a produção de doces, cucas e tortas. Mais tarde, também é proibido o pão branco e somente ainda admitido pão preto. Isso é, sem dúvida, uma intervenção na liberdade do exercício da profissão dos padeiros. E, porém, também, sem dúvida, uma intervenção que sucede "por lei". Se isso devesse bastar para a justificação da intervenção, o direito fundamental perderia, diante do legislador, toda força. O direito fundamental correria, nisso, no vazio. $O$ dever do pão preto seria constitucional.

\section{c) 0 caminho da teoria dos \\ princípios}

É a grande vantagem da teoria dos princípios que ela pode evitar um tal correr no vazio dos direitos fundamentais sem conduzir ao entorpecimento. Segundo ela, a questão de que uma intervenção em direitos fundamentais esteja justificada deve ser respondida por uma ponderação. $\mathrm{O}$ mandamento da ponderação corresponde ao terceiro princípio parcial do princípio da proporcionalidade do direito constitucional alemão. O primeiro é o princípio da idoneidade do meio empregado para o alcance do resultado com ele pretendido; o segundo, o da necessidade desse meio. Um meio não é necessário se existe um meio mais ameno, menos interventor.

É um dos argumentos mais fortes tanto para a força teórica como também para a 
prática da teoria dos princípios que todos os três princípios parciais do princípio da proporcionalidade resultam logicamente da estrutura de princípios das normas dos direitos fundamentais e essas, novamente, do princípio da proporcionalidade. ${ }^{26}$ Isso, todavia, não pode aqui ser seguido. Deve ser lançado somente um olhar sobre o terceiro princípio parcial, o princípio da proporcionalidade em sentido estrito ou da proporcionalidade, porque ele é o meio para a solução das colisões de direitos fundamentais.

O princípio da proporcionalidade em sentido estrito deixa-se formular como uma lei de ponderação, cuja forma mais simples relacionada a direitos fundamentais ${ }^{27}$ soa:

"Quanto mais intensiva é uma intervenção em um direito fundamental tanto mais graves devem ser as razões que a justificam."

Segundo a lei da ponderação, a ponderação deve suceder em três fases. Na primeira fase deve ser determinada a intensidade da intervenção. $\mathrm{Na}$ segunda fase se trata, então, da importância das razões que justificam a intervenção. Somente na terceira fase sucede, então, a ponderação no sentido estrito e próprio.

Muitos acham que a ponderação não é um procedimento racional. A possibilidade do exame de três fases mostra que o ceticismo acerca da ponderação é injustificado. Seja, para isso, lançado mais uma vez um olhar sobre o caso-tabaco e o caso-padeiro.

No caso-tabaco, a intervenção na liberdade de profissão tem somente uma intensidade muito pequena. A indústria de tabacos pode ainda ser ativa, também por propaganda. Ao fumante é tornado, como o tribunal muito bem diz, "consciente somente um fundamento de consideração que deveria, segundo o nível de conhecimento médico atual, ser universalmente consciente". ${ }^{28} \mathrm{As}$ razões que justificam a intervenção, a contenção dos prejuízos relativos à saúde causados pelo fumo que, muitas vezes, têm como conseqüência a morte, pelo contrário, são mais graves. A ponderação conduz, portanto, quase obrigatoriamente à solução da colisão: a intervenção na liberdade da profissão é constitucional. No caso-padeiro as coisas estão ao contrário. A proibição de produzir doces, cucas e tortas intervém muito intensivamente na liberdade de profissão do padeiro. Isso ainda é reforçado quando acresce a proibição do pão branco. A saúde é, como mostra o caso-tabaco, sem dúvida, um bem de alta hierarquia, mas deve ser diferenciado. Aqui, trata-se, sobretudo, de adoecimentos dos dentes pelo consumo de comidas doces e macias. Impedir isso não é insignificante, contudo, talvez, de peso mediano. Com isso, também no caso-padeiro o resultado está fixado: a regulação que está em questão seria inconstitucional. Pois bem, ambos os casos são muito simples. Existem numerosas colisões cuja solução não é tão simples, senão prepara grandes dificuldades. Casos dessa natureza existem, por exemplo, então, quan- do tanto a intervenção é muito intensiva como também as razões que a justificam são muito graves. $O$ caso tomadas-de-refém supramencionado é desse tipo. Tornam-se então necessários outros argumentos e bem possível que não se possa acordar so bre a solução. Isso, todavia, não é uma ob jeção contra a ponderação, senão uma qualidade universal de problemas práticos ou normativos.

\section{d) Vinculação e flexibilidade}

A teoria dos princípios é capaz não só de estruturar racionalmente a solução de colisões de direitos fundamentais. Ela tem ainda uma outra qualidade que, para os problemas teórico-constitucionais que devem aqui ser considerados, é de grande significado. Ela possibilita um meio-termo entre vinculação e flexibilidade. A teoria das re gras conhece somente a alternativa: validez ou não-validez. Em uma constituição como a brasileira, que conhece numerosos direitos fundamentais sociais generosamente formulados, nasce sobre esta base uma forte pressão de declarar todas as normas que não se deixam cumprir completamente simplesmente como não-vinculativas, portanto, como meros princípios programáticos. A teoria dos princípios pode, pelo contrário, levar a sério a constituição sem exigir o im possível. Ela declara as normas que não se deixam cumprir de todo como princípios que, contra outros princípios, devem ser ponderados e, assim, são dependentes de uma "reserva do possível no sentido daquilo que o particular pode exigir razoavelmente da sociedade". ${ }^{29}$ Com isso, a teoria dos princípios oferece não só uma solução do problema da colisão, senão também uma do problema da vinculação.

\section{R. Alexy, Theorie der Grundrechte (nota 21), S. 100 ff \\ 27. Para uma formulação geral relacionada a princípios, comparar R. Alexy, Theorie der Grundrechte (nota 21), S. 146. 28. BVerfGE 95,173 (187).}

29. BVerfGE 33,303 (333) 